\title{
Potencial energético de resíduos sólidos urbanos na Região do Grande ABC Paulista
}

Os resíduos sólidos urbanos (RSU) são um dos principais problemas dos grandes centros urbanos, envolvendo complexos desafios de gerenciamento. No Brasil, atualmente, apenas $59,5 \%$ dos resíduos produzidos são destinados para aterros sanitários. Os resíduos depositados nos aterros sanitários são biodegradados e possuem um potencial de produção de biogás, este apresenta cerca de $50 \%$ de gás metano, que captado no aterro pode torna-se uma fonte de calor e combustível, possibilitando a geração de energia. Neste contexto, este trabalho, estimou geração de biogás/metano e o potencial energético, a partir dos RSU produzidos nos municípios da Região do $A B C$ paulista. A região possui cerca de $56 \%$ do seu território em áreas de proteção de mananciais ou restrições ambientais, dificultando a instalação de novos aterros, e apenas o município de Santo André possui aterro sanitário próprio público, os outros seis municípios depositam seus resíduos no Aterro Lara (privado), localizado no município de Mauá. Para realização da estimativa de emissão de biogás foi utilizada uma modelagem matemática, baseado no método de decaimento de primeira ordem, do IPCC (Painel Intergovernamental para Mudanças Climáticas). Foram coletados dados referentes a geração e a composição dos RSU destes municípios ajustando os parâmetros que compõe o modelo matemático do IPCC. Em relação a emissão de metano o valor máximo determinado foi de $18.993,07 \mathrm{~m}^{3} \mathrm{CH} 4 / \mathrm{h}$, com potencial de $32,84 \mathrm{MW}$, gerando $685,95 \mathrm{MWh}$ de energia somando todos os municípios da região, podendo abastecer uma população de até 268 mil habitantes, correspondendo a 8\% da população estimada destes municípios no ano de 2047. Espera-se que os resultados desse trabalho possam contribuir para o aperfeiçoamento, da previsão da geração de biogás e metano em aterro sanitário e, que também auxiliem no planejamento em relação ao aproveitamento energético dos RSU na Região do ABC paulista depositados em aterros sanitários.

Palavras-chave: Resíduos sólidos urbanos (RSU); Biogás; Metano; Potencial energético.

\section{Energetic potential of urban solid waste in the Region of Grande Abc Paulista}

\begin{abstract}
Municipal solid waste (MSW) is one of the main problems in large urban centers, involving complex management challenges. In Brazil, currently, only $59.5 \%$ of the waste produced is sent to landfills. The waste deposited in landfill is biodegraded and has the potential to produce biogas, which has about $50 \%$ of methane gas, which captured in the landfill can become a source of heat and fuel, enabling energy generation. In this context, this work estimated the generation of biogas/methane and the energetic potential, based on MSW produced in the cities of the ABC Region of São Paulo. The region has about $56 \%$ of its territory in areas of protection of springs or environmental restrictions, making it difficult to install new landfills, with only the municipality of Santo André having its own public landfill, the other six cities deposit their waste in Lara Landfill (private), located in the municipality of Mauá. To perform the biogas emission estimate, a mathematical model was used, based on the first-order decay method of the IPCC (Intergovernmental Panel on Climate Change). Generation and composition data of MSW in these cities were collected, adjusting the parameters that make up the IPCC mathematical model. In relation to methane emissions, the maximum value found was $18,993.07 \mathrm{~m}^{3} \mathrm{CH} 4 / \mathrm{h}$, with a potential of $32.84 \mathrm{MW}$, generating $685.95 \mathrm{MWh}$ of energy, adding all the cities in the region, which could supply a population of up to 268 thousand residents, corresponding to $8 \%$ of the estimated population of these cities in the year 2047 . It is expected that the results of this work can contribute to the improvement, the forecast of the generation of biogas and methane in landfills, and that they also assist in planning to the energy use of MSW from $A B C$ paulista, deposited in landfills.
\end{abstract}

Keywords: Municipality solid waste (MSW); Biogas; Methane; Energetic potential.

Topic: Engenharia Sanitária

Reviewed anonymously in the process of blind peer.
Received: 04/02/2021

Approved: $24 / 02 / 2021$
Larissa Cruz Vieira (iD)

Universidade Federal de São Paulo, Brasil http://lattes.cnpq.br/9822605905634281 http://orcid.org/0000-0001-7620-6070

larissa.cruz@unifesp.br

\section{Giovano Candiani (iD)}

Universidade Federal de São Paulo, Brasil http://lattes.cnpq.br/9950995765229751 http://orcid.org/0000-0001-9896-4390 giovanocandiani@gmail.com

\section{Referencing this:}

VIEIRA, L. C.; CANDIANI, G.. Potencial energético de resíduos sólidos urbanos na Região do Grande ABC Paulista. Revista Ibero Americana de Ciências Ambientais, v.12, n.2, p.328-342, 2021. DOI: http://doi.org/10.6008/CBPC2179-6858.2021.002.0030 


\section{INTRODUÇÃO}

Os problemas envolvendo os resíduos sólidos urbanos (RSU) no mundo estão se tornando grandes desafios, principalmente, quando relacionados a sua destinação, riscos a sociedade e ao meio ambiente (SANTOS et al., 2019). Com o crescimento populacional e urbanização, a geração de RSU aumenta e estes biodegradados acabam emitindo gases de efeito estufa, contribuindo para o aquecimento global e as mudanças climáticas (GOUVEIA, 2012; SANTOS et al., 2019).

Os RSU são gerados nas residências, comércios, logradouros públicos e diversas atividades desenvolvidas nas cidades, incluindo os resíduos de varrição de ruas e praças. São geralmente compostos por: matéria orgânica (resíduos alimentares e de jardinagem), papéis e papelões, plásticos, vidros, metais, madeiras e outros (tecidos, borrachas, couros, entulhos etc.) (VIANA et al., 2016; VIANA et al., 2015).

De acordo com a ABRELPE (2019) no Brasil durante o ano de 2018 foram geradas 79 milhões de toneladas de resíduos, deste valor cerca de $92 \%$ foram coletados, mas apenas $59,5 \%$ foram destinados corretamente para aterros sanitários. Esses valores indicam que 29,5 milhões de toneladas de RSU tiveram como disposição final lixões e aterros controlados condições ambientalmente inadequadas (ABRELPE, 2019). Esses locais não possuem todos os sistemas de controle ambiental e procedimentos operacionais necessários para a prevenção de danos ambientais. No aterro sanitário estes impactos ambientais são mitigados, por meio da captação e tratamento dos lixiviados e biogás (BOSCOV, 2008; ABRELPE, 2012).

Desde o ano de 2010, a Política Nacional dos Resíduos Sólidos (PNRS), Lei no 12.305/10, estabelece todos os instrumentos para o enfretamento dos principais problemas ambientais, sociais e econômicos referente ao manejo correto dos resíduos sólidos (BRASIL, 2010; BRASIL, 2014). Esta lei, incentiva o desenvolvimento e aplicação de tecnologias que possibilitem o aproveitamento energético dos resíduos, portanto, promove a valorização do biogás gerado nos aterros, por meio de sua queima e produção de energia (BRASIL, 2010; SANTOS et al., 2019).

Em definição, o aterro sanitário é uma forma de disposição de resíduos no solo, em destaque os RSU, possuindo como fundamento critérios de engenharia e normas operacionais, que possibilitam confinamento seguro, promovendo controle da poluição ambiental e proteção à saúde pública, minimizando potenciais impactos ambientais (BOSCOV, 2008).

A composição gravimétrica (em peso) é uma das características importantes dos RSU, pois quanto maior a quantidade de matéria orgânica, maior a geração de biogás. Esta composição varia com o local, clima, hábitos culturais, nível educacional, atividades e desenvolvimento econômico. No Brasil, a porcentagem de resíduos orgânicos nas cidades brasileiras é elevada, variando de 50 a 70\% (BARROS, 2013), gerando um potencial de produção de energia elétrica, a partir do biogás, na ordem de 4,5 a 6,9 GW (SANTOS et al., 2018).

A biodegradação dos resíduos sólidos em aterro sanitário, ocorre por meio de processos físicos, químicos e biológicos, produzindo lixiviados e gases. Este processo envolve diferentes fases ao longo do tempo, dividindo-se em: aeróbica, anaeróbica ácida, anaeróbica metanogênica não estabilizada e anaeróbica metanogênica estabilizada (FAOUR et al., 2007). 
A fase inicial, aeróbica, é normalmente mais curta, pois o teor de oxigênio $\left(\mathrm{O}_{2}\right)$ é alto nos resíduos recentes depositados no aterro sanitário. Este oxigênio e o nitrogênio $\left(N_{2}\right)$ presentes nos resíduos no aterro são consumidos pelos microrganismos, gerando gás carbônico $\left(\mathrm{CO}_{2}\right)$, água $\left(\mathrm{H}_{2} \mathrm{O}\right)$ e calor, o que aumenta a temperatura no ambiente. Consumido todo o oxigênio, o processo passa a ser anaeróbico e a decomposição da matéria orgânica resulta na geração de ácidos orgânicos, tornando o ambiente ácido $(\mathrm{pH}<5)$ e com elevados valores de DBO (demanda bioquímica de oxigênio) e DQO (demanda química de oxigênio); esta fase é a anaeróbica ácida (subdividida ainda em hidrólise, acidogênese e acetogênese), aspectos que contribuem para o aumento da geração de gás carbônico. A fase seguinte é a metanogênica acelerada, que produz muito metano $\left(\mathrm{CH}_{4}\right)$, a partir dos ácidos da fase anterior. $\mathrm{E}$ a fase final é a metanogênese desacelerada, com menor produção de metano. No aterro, todas estas fases ocorrem simultaneamente, com duração que varia de anos a décadas (CANDIANI et al., 2015; 2018).

A mistura de gases, resultante do processo de biodegradação anaeróbica da matéria orgânica no aterro é denominada de biogás, sendo este composto essencialmente por metano e gás carbônico e seu poder calorífico está diretamente relacionado à quantidade de metano na mistura (BOSCOV, 2008).

O biogás de aterro é uma fonte de calor, sendo utilizado como combustível, a partir da remoção da sua umidade, tornando-se adequado para o uso em diversas aplicações, como de: aquecimento urbano, processos industriais e combustível para caldeiras na produção de vapor e energia elétrica, a partir da sua queima em motores e turbinas (FERRER et al., 2006; BARROS, 2012).

Tabela 1: Usinas de geração de energia elétrica, a partir de biogás de aterro sanitário em operação no Brasil

\begin{tabular}{l|l|l|l} 
Usina & Potência (MW) & Empresa Proprietária & UF \\
\hline Asja BH & 1,4 & Consorcio Horizonte Asja & MG \\
Asja Jaboatão & 14,3 & Asja Serviços Ambientais & PE \\
Asja Sabará & 7,1 & LTDA. & MG \\
Bandeirantes & 4,6 & Asja Sabará Serviços AS. & MP \\
Biotérmica Recreio & 12,7 & Biogás Energia Ambiental SA. & SP \\
Usinaverde & 0,44 & Biotérmica Energia SA. & RS \\
CTR Juiz de Fora & 4,3 & Usinaverde SA. & RJ \\
Curitiba Energia & 8,5 & Valorgas - Energia e Biogás & MG \\
Fátima do Sul & 2,55 & Curitiba energia LTDA. & PR \\
Guatapará & 5,7 & Eco Business Resíduos LTDA. & MS \\
Itajaí Biogás & 1,1 & Guatapará Energia SA. & SP \\
Nova Iguaçu & 16,9 & Itajaí Biogás e Energia SA. & SC \\
Novagerar & 4,0 & Nova Iguaçu Energia e Gás & RJ \\
Salvador & 19,7 & Novagerar Eco-energia LTDA. & RJ \\
São João Biogás & 21,5 & Termoverde Salvador SA. & BA \\
Tecipar & 5,7 & São João Energia SA. & SP \\
Termoverde Caieiras & 29,5 & Tecipar Engenharia LTDA. & SP \\
Tremembé & 4,3 & Termoverde Caieiras LTDA. & SP \\
Uberlândia & 4,3 & Tremembé Energia LTDA. & SP \\
Usitrar Manaus & 3,0 & Energas Energia LTDA. & MG \\
Usitrar Cabreúva & 2,7 & Eco Business Serviços LTDA. & AM \\
\hline Total & 174,3 MW & Eco Business Resíduos LTDA. & SP \\
Fonte: ANEEL & - & - \\
& & &
\end{tabular}

Fonte: ANEEL (2020).

No Brasil, o maior uso do biogás é na geração de eletricidade, por meio de motores de combustão interna. Os aterros implantam sistemas de captação do biogás, formados por tubulações conectadas aos drenos de gás e sistemas encaminham o biogás aos motores (instalados no aterro), que fazem a conversão 
desse biogás em eletricidade (ABREU, 2014; BARROS et al., 2014). O país vem ampliando o aproveitamento de energia dos aterros sanitários, atualmente 22 termelétricas encontram-se em operação (Tabela 1), totalizando um potencial energético de cerca de 174,3 MW (ANEEL, 2020).

Nesse contexto, a estimativa da geração de metano em aterro sanitário é importante para se realizar o aproveitamento energético. Uma previsão de metano errada, pode comprometer toda a viabilidade econômica de um projeto de aproveitamento de energia em um aterro sanitário. A estimativa de metano no aterro pode ser feita usando equações estequiométricas e expressões matemáticas (modelagens) (CANDIANI et al., 2015).

No aterro diversos fatores influenciam o processo de biodegradação dos resíduos e, portanto, na geração de metano, como: granulometria, composição, idade, umidade, temperatura, disponibilidade de nutrientes e outros (LIMA, 2002; 2004).

Os modelos matemáticos, bem como as estimativas da geração de metano em um aterro, não são simples, pois envolvem uma série de reações e condições ambientais, tornando essas estimativas complexas. Entretanto, muitos estudos laboratoriais e de campo sugerem que a geração de metano no aterro pode ser aproximada por um modelo matemático cinético de primeira ordem. E com isto, diversos modelos têm sido propostos, adotando essa premissa (NASCIMENTO et al., 2019; PIÑAS et al., 2016; SANTOS et al., 2017).

O grande desafio é mensurar todo o metano gerado em um aterro, pois uma parcela deste metano é biodegradada e/ou aprisionada no próprio aterro, dificultando dimensionar estas perdas. Por isso, a importância de se aperfeiçoar cada vez mais as estimativas da geração de metano em aterro sanitário, tornando-as mais precisas e confiáveis (BOSCOV, 2008; TEIXEIRA JUNIOR, 2016).

Normalmente, os modelos de geração de metano no aterro relacionam o volume gerado em um determinado tempo com a porcentagem de matéria orgânica inicial nos resíduos e um fator de conversão de massa de matéria orgânica em volume de gás (ABRELPE, 2012; TCHOBANOGLOUS et al., 1993).

Os modelos matemáticos mais usados na estimativa da geração de metano em aterro sanitário, são: IPCC: Modelo INPCC (IPCC, 1996; 2000), USEPA: Modelo LandGEM (USEPA, 1998) e Banco Mundial: Modelo Scholl Canyon (BANCO MUNDIAL, 2003).

Estes modelos são muito semelhantes, utilizando equações cinéticas de primeira ordem para estimar a geração de metano no aterro. Entretanto, estes modelos apresentam dois parâmetros fundamentais em suas equações: $k$ e $L_{0}$.

O k representa a taxa de geração de metano para a massa de RSU no aterro, quanto maior o valor de k, mais rapidamente a matéria orgânica no aterro é biodegradada. Essencialmente, o k é influenciado pelos seguintes fatores ambientais/climáticos: teor de umidade dos RSU, disponibilidade de nutrientes para os microrganismos, $\mathrm{pH}$ e temperatura dos RSU. Sua medida métrica é dada em unidades de $1 /$ ano ou ano-1 (CANDIANI et al., 2018).

O $L_{0}$ é a capacidade potencial de geração de metano no aterro, sendo mensurado em função da composição dos RSU, sobretudo, os resíduos orgânicos. Sua medida métrica, normalmente, é dada em metros cúbicos $\left(\mathrm{m}^{3}\right)$ por megagramas (Mg) (CANDIANI et al., 2018). 
Torna-se necessário adequar corretamente estes parâmetros em função da composição dos RSU e condições ambientais/climáticas de uma determinada localidade, buscando-se obter uma estimativa mais precisa da geração de metano no aterro e com isto, determinar o potencial energético do aterro com menor erro possível.

Na Região Metropolitana de São Paulo (RMSP) está localizada a Região do Grande ABC Paulista, sendo esta composta por sete municípios: Diadema, Mauá, Santo André, São Bernardo do Campo, São Caetano do Sul, Ribeirão Pires e Rio Grande da Serra. Desses apenas o município de Santo André possui aterro sanitário municipal público, porém este encontra-se em estágio final de vida útil (SANTO ANDRÉ, 2008). Os outros municípios, destinam seus RSU em um aterro privado (Aterro Lara), localizado no município de Mauá.

Neste contexto, esse trabalho, tem como objetivo estimar o potencial energético dos municípios da Região do $A B C$, a partir dos RSU gerados e dispostos em aterros, tendo como base o modelo matemático do IPCC para previsão da geração de metano em aterro sanitário.

\section{METODOLOGIA}

\section{Caracterização da área de estudo}

A Figura 1 mostra a localização da região do Grande ABC Paulista, que apresenta um território de 841 $\mathrm{km}^{2}$. Esta região possui uma população, de acordo com o Instituto Brasileiro de Geografia e Estatística - IBGE (2010), de 2.549.135 habitantes e, apresenta uma forte atuação nos setores comercial, industrial e de serviços. O Grande ABC Paulista possui 56\% de seu território dentro de áreas de proteção de mananciais ou com restrições ambientais, sendo que os municípios de Ribeirão Pires e Rio Grande da Serra encontram-se 100\% inseridos nestas áreas (VALVERDE et al., 2018) (Figura 1).

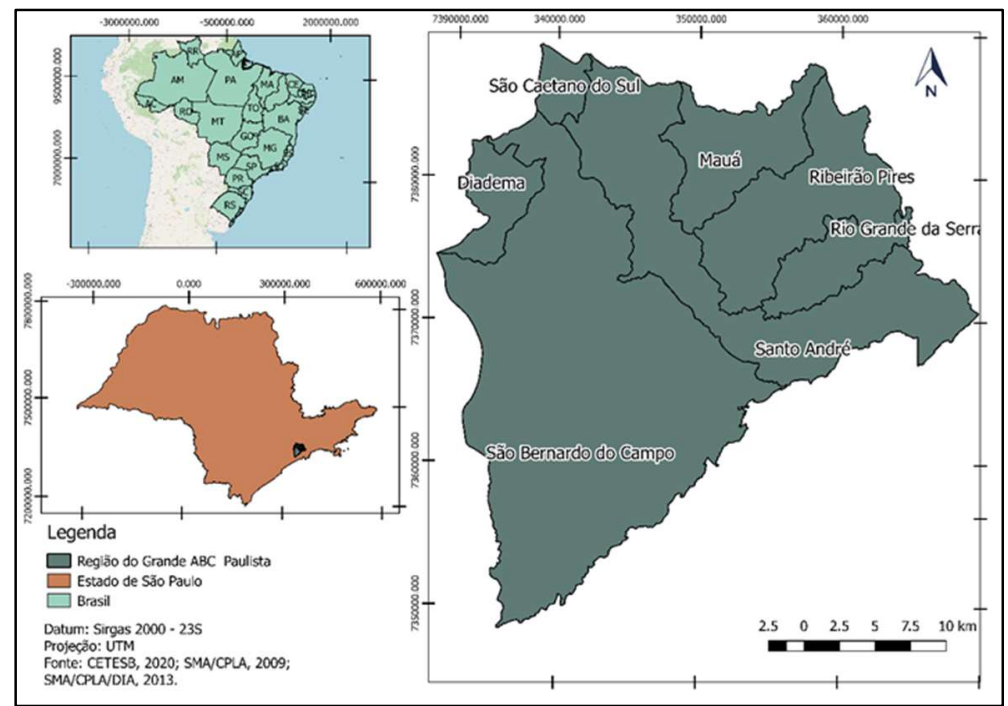

Figura 1: Localização da Região do ABC Paulista. Fonte: CETESB (2020), São Paulo (2009; 2013).

Para se estimar a geração de biogás em um aterro sanitário, é necessário quantificar a entrada de resíduos e a vida útil do aterro (geralmente períodos entre 20 e 30 anos), por isso a importância de se determinar os dados populacionais dos munícipios. Os valores populacionais dos anos de 2010 e 2018 foram utilizados para determinação da taxa de crescimento populacional dos municípios, que variou de 0,71 a 
0,78\% (IBGE, 2018) (Tabela 2).

Os dados permitiram estimar a população (Equação 1) ao longo do período de 2018 a 2047, de atividade do aterro. A Tabela 2 mostra os dados populacionais e a taxa de crescimento dos municípios estudados.

\section{Pf $($ habitante $)=\left(\mathbf{n}^{\mathrm{t}}+\mathbf{1}\right) \cdot \mathbf{P i} \quad$ Equação 1}

P.f.: População final $\mathrm{n}(\%)=$ Taxa de crescimento populacional t: tempo (anos) P.i.: População Inicial

Tabela 2: Dados populacionais e taxa de crescimento dos munícipios

\begin{tabular}{l|lll} 
Municípios & População 2010 & População 2018 & Taxa de crescimento \\
\hline Diadema & 386.039 & 420.934 & $0,74 \%$ \\
Mauá & 417.281 & 468.148 & $0,77 \%$ \\
Ribeirão Pires & 113.043 & 122.607 & $0,73 \%$ \\
Rio Grande da Serra & 44.084 & 50.241 & $0,78 \%$ \\
Santo André & 673.914 & 719.109 & $0,71 \%$ \\
São Bernardo do Campo & 765.203 & 833.240 & $0,74 \%$ \\
São Caetano do Sul & 149.571 & 149.571 & $0,75 \%$
\end{tabular}

Fonte: IBGE (2018).

\section{Coleta de Dados da Geração e Composição dos RSU}

Com a determinação do número de habitantes foi possivel estimar a geração anual de RSU. Para a realização deste cálculo foi utilizado os índices estimativos de produção per capita de RSU em função da população urbana (Tabela 3) (CETESB, 2019).

Tabela 3: Índices estimativos de produção per capita de resíduos sólidos urbanos, adotados em função da população urbana.

\begin{tabular}{l|l} 
População (habitantes) & Geração per capita (kg/hab./dia) \\
\hline De 25.001 a 100.000 & 0,8 \\
De 100.001 a 500.000 & 0,9 \\
Maior que 500.000 & 1,1
\end{tabular}

Fonte: CETESB (2019).

O valor de geração anual dos RSU foi determinado pelo produto da geração per capita $(\mathrm{kg} / \mathrm{hab} . / \mathrm{dia})$ e estimativa populacional (habitantes) para o período estudado. O valor encontrado para a produção da população do munícipio em um dia, foi convertido para tonelada (t)/ano (Tabela 4) (IBGE, 2018; CETESB, 2019).

Tabela 4: Estimativa populacional e geração dos resíduos sólidos urbanos para o ano de 2018

\begin{tabular}{l|ccc} 
Municípios & População 2018 & Geração (t/dia) 2018 & Geração (t/ano) 2018 \\
\hline Diadema & 420.934 & 378,84 & 138.277 \\
Mauá & 468.148 & 421,33 & 153.785 \\
Ribeirão Pires & 122.607 & 110,35 & 40.278 \\
Rio Grande da Serra & 50.241 & 40,19 & 14.669 \\
Santo André & 719.109 & 787,72 & 287.518 \\
São Bernardo do Campo & 833.240 & 901,23 & 328.949 \\
São Caetano do Sul & 160.275 & 144,25 & 52.651
\end{tabular}

Fonte: IBGE (2018); CETESB (2019).

Para a caracterização dos dados de geração e composição dos RSU dos municípios foram realizadas consultas aos Planos Municipais de Gestão Integrada de Resíduos Sólidos dos municípios e ao Plano Regional 
de Gestão Integrada de Resíduos Sólidos do Grande ABC - PRGIRS (Consórcio Intermunicipal Grande Abc 2016).

Os dados de gravimetria dos resíduos sólidos dos municípios de Mauá, Ribeirão Pires, Rio Grande da Serra e São Caetano do Sul não foram encontrados, pois estes municípios não realizam estudos gravimétricos. Contudo, para estes municípios foram utilizados, os valores resultantes do cálculo da média aritmética, a partir dos valores encontrados nos municípios de Diadema, Santo André e São Bernardo do Campo, dado que, são municípios ocupantes da mesma região geográfica, entretanto, existem diferenças socioeconômicas e culturais entre eles, o que representa potenciais diferenças na composição dos resíduos gerados, mas, adotou-se tal procedimento para viabilizar a realização das estimativas adequadamente, entendendo-se isto, como uma limitação do trabalho.

\section{Cálculos das Estimativas da Geração de Biogás e Metano dos RSU}

O método utilizado para realizar a estimativa de geração de metano dos RSU nos municípios foi o procedimento do IPCC (1996; 2000), modelo matemático de primeira ordem. Esse método permite quantificar a emissão de gás relacionando o tempo de deposição dos resíduos, as diferentes fases do processo de biodegradação, a taxa de decaimento e massa de RSU (ABREU, 2014; CANDIANI et al., 2015). Esse modelo é mundialmente aceito, pois relaciona a entrada das massas anuais, o tempo de atividade e outros parâmetros cinéticos envolvendo o processo de decomposição destes resíduos. O modelo cinético de primeira ordem descreve o processo de geração de metano considerando dois parâmetros cinéticos principais: Lo e k parâmetros influenciados pela caracterização dos resíduos, teores de material orgânico, temperatura, umidade, acidez e outros fatores (CANDIANI et al., 2015).

O processo de biodegradação dos resíduos não se inicia no momento da deposição no aterro, ocorrendo posteriormente com o passar do tempo e ação dos microrganismos, também influenciados pela composição dos resíduos e, principalmente, as condições climáticas, a que estes estão inseridos. A produção de biogás, propriamente dita, se dá no modelo do IPCC, após um ano do depósito do resíduo no aterro, representando um tempo de latência do resíduo no aterro. A estimativa final da produção de biogás é dada pela soma das produções anuais (PENTEADO et al., 2012).

A Equação 2 expressa a estimativa da geração de metano no aterro, gás de aterro - Landfill gas (LFG), em $\mathrm{m}^{3} \mathrm{CH}_{4} /$ ano.

$$
\mathbf{L F G}=\mathbf{k} \cdot \mathbf{R x} \cdot \mathbf{L o} \cdot \mathrm{e}^{-\mathrm{k}(\mathrm{x}-\mathrm{T})} \text { Equação } 2
$$

A estimativa da geração de metano é determinada de acordo com a deposição dos RSU anualmente no aterro. A emissão de gás (LFG) anualmente é determinada: pelo potencial de geração de metano (Lo), durante o ano correspondente $(T)$, pelos resíduos que são gerados pela população neste tempo (Rx) e são depositados no ano determinado (x), e o valor de $\mathrm{k}$ que é determinado de acordo com as características climáticas do local em que o aterro está inserido (IPCC, 1996; 2000; SANTOS et al., 2017).

A constante de biodegradação de metano $(k)$ correlaciona-se com a velocidade de biodegradação da matéria orgânica, sendo associada ao local de deposição e composição dos resíduos, condições climáticas da 
região de disposição, incluindo: temperatura média anual (TMA), precipitação média anual (PMA) e potencial de evapotranspiração (PET) (IPCC, 1996; 2000). Os valores recomendados para k são baseados no clima dos locais dos aterros (Tabela 5) (CETESB, 2010).

Tabela 5: Valores do IPCC (1996; 2000) para k.

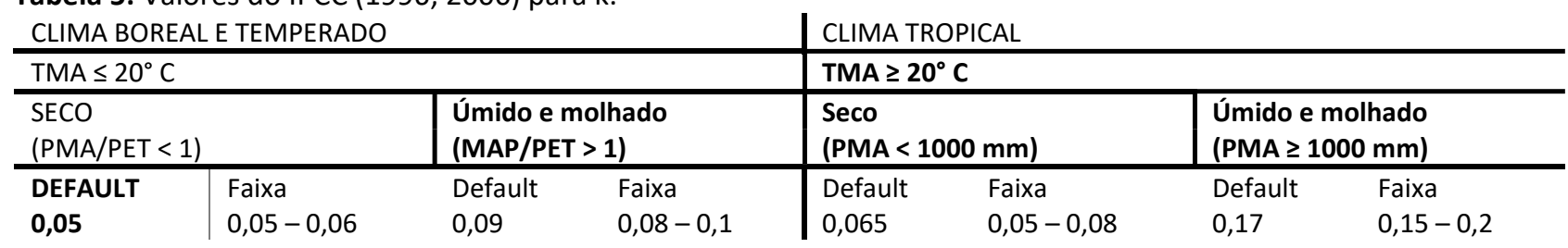

Fonte: CETESB (2010).

Conforme o INMET (2018) a região do Grande ABC Paulista, possui temperatura média anual superior a $20^{\circ} \mathrm{C}$ e pluviometria média anual superior a $1000 \mathrm{~mm}$, caracterizando o Clima Tropical Úmido e Molhado, neste contexto, sugere-se o uso do valor de k de 0,2 (MACHADO et al., 2009; CANDIANI et al., 2015; INMET, 2018). Para determinar o LFG é necessário encontrar o Lo correspondente, sendo utilizado a seguinte equação (Equação 3):

$$
\mathrm{L}_{0}=\mathrm{MCF} \cdot \mathrm{DOC} \cdot \mathrm{DOCf} \cdot \mathrm{F} \cdot \frac{16}{12} \quad \text { Equação } 3
$$

Sendo:

Lo: potencial de geração de metano do RSU ( $\mathrm{m}^{3}$ biogás/kg RSU);

MCF: fator de correção do metano, referente ao gerenciamento dos locais de disposição de RSU (adimensional) = 1 (aterros controlados; ABREU, 2014; CETESB, 2002); DOC: fração de carbono degradável (g Carbono/g RSU); DOCf: fração de DOC que decompõe (g Carbono/g RSU);

F: fração de metano no biogás $=50 \%$; 16/12: razão de conversão de carbono (C) a metano $\left(\mathrm{CH}_{4}\right)$.

O modelo do IPCC permite a realização de uma distinção da localização, temperatura e tipo de RSU, características fundamentais para se estimar a produção de metano nos aterros. Também classifica os locais de deposição de resíduos em três categorias: aterro sanitário, aterro controlado e lixão; possibilitando estabelecer um fator de correção do metano, condizente com qualidade de operação do local de disposição (CETESB, 2010; ABREU, 2014; IPCC, 1996; 2000).

Para aterros sanitários o valor desse fator é igual a 1, pois se considera que as condições para disposição dos resíduos por parte do aterro ocorrem de forma adequada (Tabela 6) (ABREU, 2014; IPCC, 1996; 2000; CETESB, 2010).

Tabela 6: Dados de valores para o fator de correção de metano.

\begin{tabular}{l|l} 
TIPO DE LOCAL DE DEPOSIÇÃO & FATOR DE CORREÇÃO \\
\hline LIXÃO & 0,4 \\
ATERRO CONTROLADO & 0,8 \\
ATERRO SANITÁRIO & 1,0
\end{tabular}

Fonte: CETESB (2010); IPCC (1996).

Outro parâmetro do modelo, refere-se ao valor do Carbono Orgânico Degradável (DOC) que corresponde ao tempo necessário para a biodegradação dos resíduos, determinado conforme a composição dos RSU depositados nos aterros (IPCC, 1996; 2000; ABREU, 2014). Os resíduos orgânicos são divididos em pelo menos cinco categorias principais (Tabela 7): papel e papelão; resíduos de jardim; resíduos alimentares; 
tecidos; e madeira (CETESB, 2010; IPCC, 1996; 2000).

Tabela 7: Valores recomendados para o carbono orgânico degradável (DOC) para cada componente dos resíduos. COMPONENTE

\begin{tabular}{ll|l} 
A. & PAPELÃO E PAPEL & 40 \\
B. & RESÍDUOS DE JARDIM & 17 \\
C. & RESÍDUOS DE ALIMENTOS & 15 \\
D. & TECIDOS & 40 \\
E. & MADEIRA & 30
\end{tabular}

Fonte: IPCC $(1996 ; 2000)$. PORCENTAGEM DE DOC

DOC é calculado pela seguinte equação (Equação 4):

$$
\mathrm{DOC}=0,40 \mathrm{~A}+0,17 \mathrm{~B}+0,15 \mathrm{C}+0,40 \mathrm{D}+0,30 \mathrm{E} \text { Equação } 4
$$

Sendo:

A: papelão e papel; B: resíduos de jardinagem; C: resíduos alimentares;

D: tecidos;

E: madeira.

A Fração do Carbono Orgânico Degradável Assimilado $\left(\mathrm{DOC}_{f}\right)$ é a porção efetiva da degradação do material disposto no aterro, o valor é dado pela equação 5 de acordo com a temperatura da zona anaeróbia (IPCC, 1996; 2000; TABASARAN, 1982).

$$
\mathrm{DOC}_{f}=0,014 \mathrm{~T}(\stackrel{\mathrm{o}}{\mathrm{C}})+0,028 \text { Equação } 5
$$

Devido ao caráter exotérmico das reações anaeróbicas ocorre a produção de calor na zona anaeróbica, ocasionado pelas reações microbianas, formato e profundidade do aterro. Em aterros sanitários os resíduos são enterrados em maiores profundidades, portanto, não ocorre influência das variações de temperaturas externas no sistema (RETTENBERGER et al., 1980; ROVERS, 1977; GONÇALVES, 2018).

A temperatura da zona anaeróbicas são reguladas pela região mesófila do processo de biodegradação, entre 30 a $40^{\circ} \mathrm{C}$, que varia em função do tipo de resíduo e localidade em geral. Em zonas com temperatura de $35^{\circ} \mathrm{C}$ cerca de $80 \%$ do DOC é convertido em biogás e $50 \%$ do volume desse contém metano (BINGEMER et al., 1987; GONÇALVES, 2018).

Com a determinação de LFC, é possível estimar o Potencial Energético ( $P x)$ utilizando-se a Equação 6 e considerando-se que a porcentagem de metano no biogás é de $50 \%$, a densidade do metano é de 0,717 $\mathrm{kg} / \mathrm{m}^{3}$ e o poder calorífico inferior $(\mathrm{PCl})$ é de $8.500 \mathrm{kcal} / \mathrm{m}^{3} \mathrm{CH}_{4}$.

$$
P \boldsymbol{x}=\frac{\mathrm{LFG} \cdot \mathbf{n} \cdot \mathrm{PCI}}{\mathbf{8 6 0 . 0 0 0}} \quad \text { Equação } 6
$$

Sendo:

$L F G$ = vazão de metano $\left(\mathrm{m}^{3} \mathrm{CH} 4 / \mathrm{h}\right)$; Fator de conversão: $1 \mathrm{kcal} / \mathrm{h}=(1 / 860.000) \mathrm{MW}$; $P C I=8.500 \mathrm{kcal} / \mathrm{m}^{3} \mathrm{CH} 4$; $n=$ eficiência do motor $=0,35$ (BARROS, 2013).

O potencial energético foi convertido em energia, pela seguinte equação 7:

$$
E n=P x \cdot m o \cdot t \text { Equação } 7
$$

Os resultados encontrados de potência e energia de cada um dos municípios foram somados para 
determinar quantos habitantes os resíduos do grande $A B C$ paulista podem abastecer. $O$ consumo per capita de energia elétrica na região é de 2,553 kWh/hab. (BRASIL, 2019).

\section{RESULTADOS E DISCUSSÃO}

\section{Estimativa populacional e geração de resíduos sólidos}

A estimativa da população foi realizada de acordo com equação 1 e a tabela 8 representando a projeção do crescimento populacional considerando-se um período de 30 anos de vida útil de um aterro sanitário. É possível observar um incremento total na população de 2.774 .554 habitantes no ano de 2018 para 3.436.452 habitantes em 2047 (Tabela 8). O crescimento populacional afeta a geração per capita dos resíduos nas cidades, portanto, a partir dos valores da população (Tabela 3) foram determinados os valores da geração de resíduos em toneladas (Tabela 9) (CETESB, 2018; IBGE, 2018).

Tabela 8: Crescimento populacional dos munícipios entre os anos de 2018 e 2047.

\begin{tabular}{l|ll} 
MUNICÍPIOS & 2018 & 2047 \\
\hline DIADEMA & 420.934 & 521.352 \\
MAUÁ & 468.148 & 579.829 \\
RIBEIRÃO PIRES & 122.607 & 151.856 \\
RIO GRANDE DA SERRA & 50.241 & 62.227 \\
SANTO ANDRÉ & 719.109 & 890.660 \\
SÃO BERNARDO DO CAMPO & 833.240 & 1.032 .018 \\
SÃO CAETANO DO SUL & 160.275 & 198.510 \\
\hline TOTAL & 2.774 .554 & 3.436 .452
\end{tabular}

Fonte: realizado com base em IBGE (2018) e CETESB (2018).

A partir dos dados de estimativa populacional e geração de RSU (Tabelas 8 e 9) foi possível determinar, as taxas de geração per capita de RSU na região, que variaram de 0,9 kg/hab./dia a 1,1 $\mathrm{kg} / \mathrm{hab} . / \mathrm{dia}$.

Tabela 9: Geração de Resíduos Sólidos Urbanos.

\begin{tabular}{l|ll} 
MUNICÍPIOS & 2018 & 2047 \\
\hline DIADEMA & 138.277 & 209.323 \\
MAUÁ & 153.785 & 232.802 \\
RIBEIRÃO PIRES & 40.278 & 49.885 \\
RIO GRANDE DA SERRA & 14.669 & 18.170 \\
SANTO ANDRÉ & 287.518 & 357.600 \\
SÃO BERNARDO DO CAMPO & 328.949 & 414.355 \\
SÃO CAETANO DO SUL & 52.651 & 65.211
\end{tabular}

Fonte: realizado com base em IBGE (2018) e CETESB (2018).

\section{Dados gravimétrico, geração de metano e potencial energético}

Na Tabela 10 é possível observar os dados gravimétricos encontrados para cada um dos municípios e com base nesses dados, os cálculos de $L_{\circ}$. Os municípios de Mauá, Ribeirão Pires, Rio Grande da Serra e São Caetano do Sul possuem valores de $L_{o}$ iguais, ocasionado pelos valores gravimétricos destes municípios terem sido determinados pelas médias dos valores encontrados para São Bernardo do Campo, Diadema e Santo André. Entre os munícipios o de Santo André é o que possui o menor valor de $\mathrm{L}_{0}$, com $110,74 \mathrm{~m}^{3} \mathrm{CH}_{4} / \mathrm{tRSU}$, enquanto São Bernardo do Campo possui valor de $\mathrm{L}_{\mathrm{o}}$ igual a 126,96 $\mathrm{m}^{3} \mathrm{CH}_{4} / \mathrm{tRSU}$. Essa distinção entre os valores é causada pela diferença gravimétrica dos resíduos gerados em cada um dos munícipios. 
Tabela 10: Dados gravimétricos dos resíduos sólidos urbanos e valor de geração de metano (Lo)

\begin{tabular}{|c|c|c|c|c|c|c|}
\hline \multirow[t]{2}{*}{ Municípios } & \multicolumn{5}{|c|}{ Composição Gravimétrica dos RSUs Orgânicos (\%) } & \multirow{2}{*}{$\begin{array}{l}\text { Valor } \mathrm{L}_{0} \mathrm{~m}^{3} \mathrm{CH}_{4} / \\
\mathrm{t}_{\mathrm{RSU}}\end{array}$} \\
\hline & $\begin{array}{l}\text { Matéria } \\
\text { Orgânica }\end{array}$ & $\begin{array}{l}\text { Resíduos } \\
\text { têxteis }\end{array}$ & $\begin{array}{l}\text { Papel/ } \\
\text { Papelão }\end{array}$ & $\begin{array}{l}\text { Resíduos } \\
\text { jardinagem }\end{array}$ & Madeira & \\
\hline Diadema & 47,5 & 7,4 & 15,4 & 1,0 & 0,3 & 118,20 \\
\hline Mauá & 49,9 & 5,8 & 16,2 & 0,4 & 0,8 & 118,83 \\
\hline Ribeirão Pires & 49,9 & 5,8 & 16,2 & 0,4 & 0,8 & 118,83 \\
\hline $\begin{array}{l}\text { Rio Grande da } \\
\text { Serra }\end{array}$ & 49,9 & 5,8 & 16,2 & 0,4 & 0,8 & 118,83 \\
\hline Santo André & 56,3 & 4,3 & 12,68 & 0,1 & 0,8 & 110,74 \\
\hline $\begin{array}{l}\text { São Bernardo } \\
\text { do Campo }\end{array}$ & 45,8 & 5,6 & 20,4 & 0,4 & 1,3 & 126,96 \\
\hline $\begin{array}{l}\text { São Caetano do } \\
\text { Sul }\end{array}$ & 49,9 & 5,8 & 16,2 & 0,4 & 0,8 & 118,83 \\
\hline
\end{tabular}

Fonte: realizado com base em Diadema (2012), Santo André (2012), São Bernardo do Campo (2010), Cardoso (2016) e IPCC (1996; 2000).

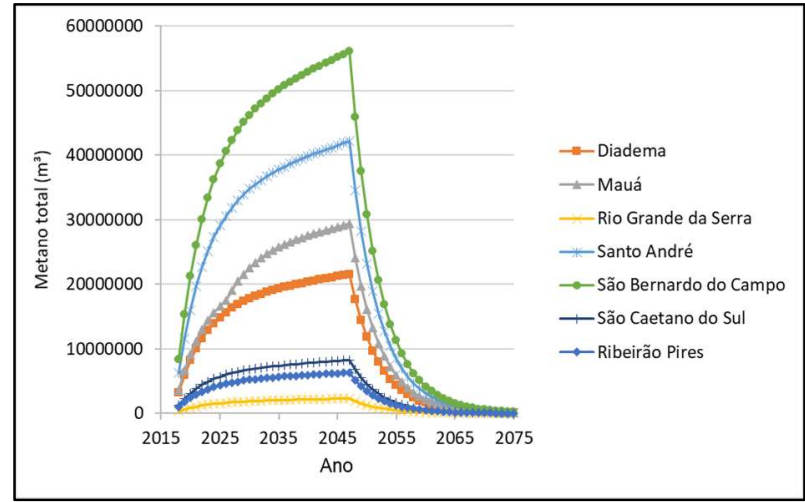

Figura 1: Metano gerado pelos RSUs dos municípios do $A B C$. Fonte: realizado com base em IPCC (1996; 2000).

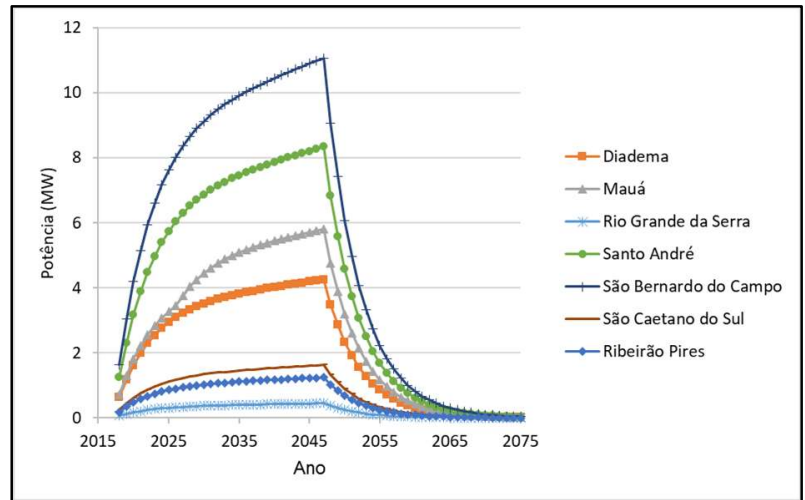

Figura 2: Potência gerada pelos RSUs dos municípios do ABC. Fonte: realizado com base em IPCC (1996; 2000).

Tabela 11: Valores máximos de potência e energia pelos RSUs dos municípios do ABC.

\begin{tabular}{l|l|l} 
MUNICÍPIOS & POTÊNCIA (MW) & ENERGIA (MWH) \\
\hline DIADEMA & 4,26 & 88,95 \\
MAUÁ & 5,81 & 121,31 \\
RIBEIRÃO PIRES & 1,25 & 27,01 \\
RIO GRANDE DA SERRA & 0,45 & 9,49 \\
SANTO ANDRÉ & 8,33 & 174,00 \\
SÃO BERNARDO DO CAMPO & 11,07 & 231,14 \\
SÃO CAETANO DO SUL & 1,63 & 34,05 \\
\hline POTENCIAL TOTAL GERADO & $\mathbf{3 2 , 8 0}$ & $\mathbf{6 8 5 , 9 5}$
\end{tabular}

O crescimento populacional da região de estudo terá um acréscimo aproximado de 661.898 habitantes até o ano de 2047, sendo entre os municípios, o de São Bernardo do Campo o mais populoso, com crescimento de 833.240 indivíduos para 1.032.018, seguindo pelo município de Santo André com 890.660, ambos municípios correspondem a 55\% da população total da região. Devido a maior parcela populacional, esses municípios também são os responsáveis pelas maiores taxas de geração de resíduos, por consequência, possuem as maiores curvas de geração de metano e potencial energético. Observando as informações apresentadas na Figura 2 o município de São Bernardo do Campo emitirá um valor de 56.064.607,85 $\mathrm{m}^{3} \mathrm{CH}_{4} / \mathrm{ano}$, e o de Santo André, 42.205.278,34 $\mathrm{m}^{3} \mathrm{CH}_{4}$ /ano, com potência em MW de 11,07 e 8,33 respectivamente (Figura 3; Tabela 11).

Em relação a Diadema e Mauá são os municípios com maior crescimento populacional após São Bernardo do Campo e Santo André, sendo 33\% da população da região no ano de 2047, com cerca de 1.134.029 habitantes. A emissão de metano para Mauá de $29.424 .596,67 \mathrm{~m}^{3} \mathrm{CH}_{4} /$ ano e Diadema em 
21.574.544,11 $\mathrm{m}^{3} \mathrm{CH}_{4}$ /ano (Figura 2), gerando um potencial energético total de 10,07 MW (Figura 3; Tabela 11).

Os municípios de São Caetano do Sul, Ribeirão Pires e Rio Grande da Serra são os menos populosos, correspondendo a $12 \%$ a população da região, totalizando 421.593 habitantes, consequentemente, serão os municípios que produzirão o menor valor de metano e potencial energético. Na Figura 2 é possível observar que o município de São Caetano do Sul produzirá 8.258.530,84 $\mathrm{m}^{3} \mathrm{CH}_{4} /$ ano, seguido por Ribeirão Pires com 6.371.608,23 $\mathrm{m}^{3} \mathrm{CH}_{4} /$ ano e Rio Grande da Serra com o menor valor, correspondendo a $2.301 .138,42$ $\mathrm{m}^{3} \mathrm{CH}_{4}$ /ano, estes municípios produzirão um total de 3,33 MW (Figura 3; Tabela 11).

A Tabela 11 descreve os valores encontrados para produção energética (Equação 7) em cada um dos municípios. Os municípios estudados possuem potencial energético de 32,80 MW (Tabela 11), portanto é uma quantidade energética interessante. $O$ valor total produzido de energia pelos resíduos dos municípios estudados é de 685,95 MWh, relacionando com o consumo de energia por habitante na região, é possível abastecer 268.683 mil pessoas, atendendo a população dos municípios de Ribeirão Pires, Rio Grande da Serra ou São Caetano do Sul, por exemplo (BRASIL, 2019).

De acordo com o Ministério do Meio Ambiente (MMA), os consórcios públicos municipais são uma forma de operação conjunta para o gerenciamento de resíduos sólidos urbanos, por parte de pequenos municípios, permitindo uma gestão adequada integrada dos RSUs, representando ganhos ambientais, econômicos e sociais (BRASIL, 2014). Observando os municípios na região de forma isolada, os seus potenciais energéticos não seriam suficientes para suprir individualmente suas respectivas populações, mas, considerando a situação de fragilidade ambiental regional, com grande parte dos municípios localizados em áreas de proteção de mananciais ou de restrições ambientais, a ação conjunta, por meio de um consórcio, poderia proporcionar benefícios a destinação dos resíduos destes municípios e potencialmente viabilizar o aproveitamento energético dos seus resíduos.

Nos Estados Unidos, por exemplo, se desenvolve um programa de aproveitamento de energia de aterro denominado de Landfill Methane Outreach Program (LMOP) criado pela United States Environmental Protection Agency (EPA), este é um programa voluntário visando a redução das emissões de metano geradas pelos aterros sanitários no país, a partir da recuperação e uso do biogás gerado (EPA, 2020).

Atualmente, existem cerca de 510 projetos envolvendo o aproveitamento da energia gerada pelo biogás dos RSU em aterros nos EUA, com produção estimada de 2,79 GW. Entre os benefícios gerados por esse programa estão, a redução da emissão de gases de efeito estufa, redução da poluição do ar devido a diminuição do uso de recursos não renováveis e fortalecimento da economia local e das comunidades nas regiões de implementação (EPA, 2020).

Ao comparar o Brasil com o caso do Estados Unidos, pode-se dizer que é ainda incipiente a utilização de biogás de aterro para a produção de energia elétrica, principalmente considerando-se o seu alto potencial de produção, entre 4,5 e 6,9 GW, mas com exploração de apenas 174,3 MW, nas 22 usinas em operação nos aterros sanitários (Tabela 1) (EPA, 2020; SANTOS et al., 2018; ANEEL, 2010). Estima-se que o valor para energia elétrica de biogás de aterro é de US\$ 50,00 por MWh, representando ganhos econômicos efetivos 
para os municípios que desenvolverem projetos de aproveitamento energético em seus aterros sanitários (LA ROVERE et al., 2005; CANDIANI et al., 2015). Além do valor monetário agregado a essa utilização, segundo Santos et al. (2018) a utilização desse potencial energético auxiliaria na diminuição de 4,93\% das emissões de carbono, devido a não emissão no meio ambiente (SANTOS et al., 2018).

O gás metano gerado no processo de biodegradação dos resíduos sólidos possui um valor de contenção de calor na estratosfera de pelo menos 21 vezes maior que o dióxido de carbono. Durante o processo de conversão do metano em energia elétrica, ocorre uma diminuição dos impactos ambientais gerados, promovendo assim uma redução da emissão de gases de efeito estufa para a atmosfera (PENTEADO et al., 2012; BRASIL, 2016; CETESB, 2016). O potencial energético envolvendo o aproveitamento do biogás produzido em aterros sanitários é promissor, possibilitando a obtenção de ganhos ambientais, sociais e econômicos para a região e seus municípios.

\section{CONCLUSÕES}

Este trabalho teve como objetivo determinar a emissão de metano, de acordo com o modelo do IPCC (1996; 2000), dos sete municípios localizados na região do Grande ABC Paulista, quantificando o seu potencial energético, com base na estimativa de crescimento populacional e geração de RSU (CETESB, 2010; IPCC, 1996; 2000; IBGE, 2010). De acordo com os dados gravimétricos dos municípios encontrados e suas médias, parâmetros climáticos da região dos municípios e dados populacionais, determinou-se a emissão de 18.993,07 $\mathrm{m}^{3} \mathrm{CH}_{4} / \mathrm{h}$ sendo capaz de produzir 685,95 MWh de energia. Devido a este potencial de geração de energia os resíduos dos municípios estudados oferecerão abastecimento para até 268 mil habilitantes, valor correspondente a 8\% da população total da região no ano de 2047.

A utilização do biogás emitido pelo processo de biodegradação dos RSU é uma fonte energética renovável, e a instalação de usinas termoelétricas para captação e geração de energia pode gerar impactos socioambientais positivos na região. Este processo poderá contribuir para a sustentabilidade ambiental, desenvolvimento de trabalhos e geração de renda, sensibilização da população local para o favorecimento de práticas sustentáveis, auxiliando no gerenciamento dos resíduos e possibilitando a destinação correta destes, principalmente em função das restrições ambientais em termos de ocupação da terra, existentes na região de estudo.

Os resíduos da região possuem potencial energético para ser explorado, porém, torna-se necessário determinar a viabilidade econômica e ambiental da implementação de uma usina termelétrica, envolvendo os custos de investimento e impactos socioambientais. A implantação de um consórcio intermunicipal na região, poderia efetivamente proporcionar benefícios a destinação dos resíduos sólidos e, principalmente viabilizar o aproveitamento energético.

\section{REFERÊNCIAS}

ABRELPE. Associação Brasileira de Empresas de Limpeza Pública e Resíduos Especiais. Atlas Brasileiro de Emissões de GEE e Potencial Energético na Destinação de Resíduos
Sólidos. São Paulo: ABRELPE, 2012.

ABRELPE. Associação Brasileira de Empresas de Limpeza 
Pública e Resíduos Especiais. Panorama dos Resíduos Sólidos no Brasil - 2018/2019. São Paulo: ABRELPE, 2019.

ABREU, F. V.. Biogás: economia, regulação e sustentabilidade. Rio de Janeiro: Interciência, 2014.

ANEEL. Agência Nacional de Energia Elétrica. Sistema de Informações de Geração da ANEEL: Usinas e Agendes de Geração. Brasil: 2020.

BANCO MUNDIAL. Manual para a Preparação de Gás de Aterro Sanitário para Projetos de Energia na América Latina e Caribe. Rio de Janeiro: BANCO MUNDIAL, 2013.

BARROS, R. M.. Tratado sobre resíduos sólidos: gestão, uso e sustentabilidade. Rio de Janeiro: Interciência, 2013.

BARROS, R. M.; TIAGO FILHO, G. L.; SILVA, T. R.. The electric energy potential of landfill biogas in Brazil. Energy Policy, v.65, p.150-164, 2014. DOI:

http://dx.doi.org/10.1016/j.enpol.2013.10.028

BARROS, R. T. V.. Elementos de resíduos sólidos. Belo Horizonte: Tessitura, 2012.

BINGEMER, H. G.; CRUTZEN, P. J.. The production of methane from solid wastes. Journal of Geophysical Research, v.92, n.D2, p.2181-2187, 1987. DOI: https://doi.org/10.1029/JD092iD02p02181

BOSCOV, M. E. G.. Geotecnia ambiental. São Paulo: Oficina de Textos, 2008.

BRASIL. Lei n. 12.305, de $\mathbf{2}$ de agosto de 2010. Presidência da República/Casa Civil/Subchefia para Assuntos Jurídicos. Institui a Política Nacional de Resíduos Sólidos; altera a Lei no 9.605 , de 12 de fevereiro de 1998; e dá outras providências. Brasília: DOU, 2010.

BRASIL. Ministério da Ciência, Tecnologia e Inovação. Mecanismo de Desenvolvimento Limpo. Brasília: MCTIC 2016.

BRASIL. Ministério do Meio Ambiente. Estudo sobre o potencial de geração de energia a partir de resíduos de saneamento (lixo, esgoto) visando incrementar o uso e biogás como fonte alternativa de energia renovável. Brasília: Programa das Nações Unidas para o Desenvolvimento, 2010.

BRASIL. Ministério do Meio Ambiente. Mecanismo de Desenvolvimento Limpo. Brasília: MMA, 2014.

BRASIL. Ministério de Minas e Energia. EPE. Empresa de Pesquisa Energética. Anuário Estatístico de Energia Elétrica. Brasília: MME, 2019.

CANDIANI, G.; MOREIRA, J. M. L.. Avaliação dos parâmetros cinéticos da geração de metano em uma célula experimental de resíduos sólidos. Engenharia Sanitária Ambiental, v.23, n.3, p.459-470, 2018.

CANDIANI, G.; MOREIRA, J. M. L.. Estudo da Geração de Metano em uma Célula de Aterro Sanitário. Jundiaí: Paco, 2015.

CARDOSO, E. G.. Estudo potencial energético proveniente de resíduos sólidos urbanos na reunião do grande $A B C$. Dissertação (Mestrado em Energia) - Universidade Federal do ABC, Santo André, 2016.

CETESB. Companhia Ambiental do Estado de São Paulo. Emissões de gases de efeito estufa no tratamento e disposição de resíduos. São Paulo: Companhia Ambiental do Estado de São Paulo, 2009.

CETESB. Companhia Ambiental do Estado de São Paulo. Emissões de metano aceleram aquecimento global mais que $\mathrm{CO}_{2}$. São Paulo: CETESB, 2016.

CETESB. Companhia Ambiental do Estado de São Paulo. Enquadramento dos Corpos Hídricos. São Paulo: Água Interiores, 2020.

CETESB. Companhia Ambiental do Estado de São Paulo. Inventário Estadual dos Resíduos Sólidos Urbanos. São Paulo: CETESB, 2019.

CONSÓRCIO INTERMUNICIPAL GRANDE ABC. Plano Regional de Gestão Integrada de Resíduos Sólidos do Grande ABC. Santo André: FESPSP, 2016.

DIADEMA. Plano Municipal de Gestão Integrada dos Resíduos Sólidos de Diadema. Diadema: DIADEMA, 2012.

EPA. United States Environmental Protection Agency. Landfill Methane Outreach Program: Benefits of Landfill Gas Energy Projects. United States Environmental Protection Agency, 2020.

FAOUR, A. A.; REINHART, D. R.; YOU, H.. First-order kinetic gas generation model parameters for wet landfills. Waste Management, v.27, n.7, p.946-953, 2007. DOI: https://doi.org/10.1016/j.wasman.2006.05.007

FERRER, J. T. V.; ALVES, J. W. S.. Biogás: projetos e pesquisas no Brasil. São Paulo: CETESB, 2006

GONÇALVES, M. N.. Os efeitos da temperatura na produção de biogás em biodigestores. Dissertação (Mestrado em Engenharia Elétrica) - Universidade Federal de Uberlândia, Uberlândia, 2018.

GOUVEIA, N.. Solid urban waste: socio-environmental impacts and prospects for sustainable management with social inclusion. Ciência \& Saúde Coletiva, v.17, n.6, p.15031510, 2012. DOI: https://doi.org/10.1590/S1413$\underline{81232012000600014}$

IBGE. Instituto Brasileiro de Geografia e Ciências. População. Brasília: IBGE, 2010.

IBGE. Instituto Brasileiro de Geografia e Ciências. População. Brasília: IBGE, 2018.

INMET. Instituto Nacional de Meteorologia. Normais climatológicos. Brasília: INMET, 2018.

IPCC. Intergovernmental Panel on Climate Change. Guidelines for National Greenhouse Inventories: Reference Manual. IPCC, 1996.

IPCC. Intergovernmental Panel on Climate Change. Good Practice Guidance and Uncertainly Management in 
National Greenhouse Gas Inventories. Tóquio: IPCC, 2000.

LA ROVERE, E. L.; COSTA, C. V.; DUBEUX, C. B. S.. Aterros Sanitários no Brasil e o Mecanismo de Desenvolvimento Limpo (MDL): Oportunidades de promoção de desenvolvimento socioambiental. 2005.

LIMA, L. M. Q.. Biorremediação de Lixões. São Paulo: Aplicações da Biotecnologia ao Meio Ambiente, 2002.

LIMA, L. M. Q.. Lixo: Tratamento e Biorremediação. São Paulo: Hemus, 2004.

MACHADO, S. L.; CARVALHO, M. F.; VILAR, O. M.; GOURC, J. P.; NASCIMENTO, J. C. F.. Methane Generation in Tropical Landfills: simplified methods and fields results. Waste Management, v.29, p.153-161, 2009.

NASCIMENTO, M. C. B.; FREIRE, E. P. F.; DANTAS, F. A. S.; GIANSANTE, M. B.. Estado da arte dos aterros de resíduos sólidos urbanos que aproveitam o biogás para geração de energia elétrica e biometano no Brasil. Engenharia Sanitária Ambiental, v.24, n.1, p.143-155, 2019. DOI: https://doi.org/10.1590/s1413-41522019171125

PENTEADO, R.; CAVALLI, M.; MAGNANO, E.; CHIAMPO, F.. Application of the IPCC model to Brazilian landfill: First results. Revista: El Sevier, Energy Policy, v.42, p.551-556, 2012. DOI: $\underline{\text { https://doi.org/10.1016/i.enpol.2011.12.023 }}$

PIÑAS, J. A. V.; VENTURINI, O. J.; LORA, E. E. S.; OLIVEIRA, M. A.; ROALCABA, O. D. C.. Aterros sanitários para geração de energia elétrica a partir da produção de biogás no Brasil: comparação dos modelos LandGEM (EPA) e Biogás (CETESB). Revista Brasileira de Estudos Populacionais, v.33, n.1, p.175-188, 2016. DOI: http://dx.doi.org/10.20947/S0102$\underline{309820160009}$

RETTENBERGER, G.; TABASARAN, O.. Untersuchungen zur entstehung, austbreitung und ableitung von zersetzungsgasen in Abfallablagerungen.

Umweltbundesamt, 1980.

ROVERS, F. A.; TREMBLAY, J. J.; MOOIJI, H.. Procedures for landfill gas monitoring and control, Proceedings of an international seminar. Ottawa: Fish and Environ. Can., Waste Manage. Br., 1977.

SANTO ANDRÉ. Serviço Municipal de Saneamento Ambiental de Santo André. Gestão Integrada de Resíduos Sólidos de Santo André. Santo André: SEMASA, 2008.

SANTO ANDRÉ. Serviço Municipal de Saneamento Ambiental de Santo André. Plano Municipal de Gestão Integrada de Resíduos Sólidos. Santo André: SEMASA, 2012.

SANTOS, I. F. S.; VIEIRA, N. D. B.; NÓBREGA, L. G. B.; BARRO, R. M.; FILHO, G. L. T.. Assessment of potential biogas production from multiple organic wastes in Brazil: Impact on energy generation, use, and emissions abatement.

Resources, Conservatio \& Recyclin, v.131, p.54-63, 2018.

DOI: https://doi.org/10.1016/i.resconrec.2017.12.012

SANTOS, M. M.; ROMANEL, C.; ELK, A. G. H. P. V.. Análise da eficiência de modelos de decaimento de primeira ordem na previsão da emissão de gás de efeito estufa em aterros sanitários brasileiros. Engenharia Sanitária Ambiental, v.22, n.6, p.1151-1162, 2017. DOI: https://doi.org/10.1590/s1413$\underline{41522017156311}$

SANTOS, R. E.; SANTOS, I. F. S.; BARROS, R. M.; BERNAL, A. P.; FILHO, G. L. T.; SILVA, F. G. B.. Generating electrical energy through urban solid waste in Brazil_An economic and energy comparative analysis. Journal of Environmental Management, v.231, p.198-206, 2019. DOI: https://doi.org/10.1016/j.jenvman.2018.10.015

SÃO BERNARDO DO CAMPO. Prefeitura de São Bernardo do Campo. Plano Municipal de Resíduos Sólidos do Município de São Bernardo do Campo. Prefeitura de São Bernardo do Campo. São Bernardo do Campo, 2010.

SÃO PAULO. Secretaria de Infraestrutura e Meio Ambiente do Estado de São Paulo. Limite da Bacia Billings. São Paulo: Coordenadoria de Planejamento Ambiental, 2013.

SÃO PAULO. Secretaria de Infraestrutura e Meio Ambiente do Estado de São Paulo. Coordenadoria de Planejamento Ambiental. Departamento de Informações Ambientais. Munícipios do Estado de São Paulo 1980. São Paulo: Departamento de Informações Ambientais, 2013.

TABASARAN, O.. Abfallbeseitigungu nd Abfallwirtschaft. Dfisseldorf: VDI Verlag, 1982.

TCHOBANOGLOUS, G.; THEISEN, H.; VIGIL, S.. Integrated Solid Waste Management: Engineering Principles and Management Issues. 2 ed. Washington: McGrawHill, 1993.

TEIXEIRA JUNIOR, L. C.. Biogás: alternativa para geração de energia. Curitiba: Appris, 2016.

USEPA. United States Environmental Protection Agency. Landfill Gas Emissions Model: Version 3.02 User's Guide. 1998.

VALVERDE, M. C.; CARDOSO, A. O.; BRAMBILA, R.. O padrão de chuvas na região do $A B C$ Paulista: os extremos e seus impactos. Revista Brasileira de Climatologia, v.14, n.22, p.165-187, 2018. DOI: http://dx.doi.org/10.5380/abclima.v22i0.45929

VIANA, E.; CANDIANI, G.. Classificação de resíduos sólidos: uma visão multidimensional. Curitiba: CRV, 2016.

VIANA, E.; SILVEIRA, A. I.; MARTINHO, G.. Caracterização de resíduos sólidos: uma abordagem metodológica $\mathrm{e}$ propositiva. São Paulo: Biblioteca 24 horas, 2015.

A CBPC - Companhia Brasileira de Produção Científica (CNPJ: 11.221.422/0001-03) detém os direitos materiais desta publicação. Os direitos referem-se à publicação do trabalho em qualquer parte do mundo, incluindo os direitos às renovações, expansões e disseminações da contribuição, bem como outros direitos subsidiários. Todos os trabalhos publicados eletronicamente poderão posteriormente ser publicados em coletâneas impressas sob coordenação da Sustenere Publishing, da Companhia Brasileira de Produção Científica e seus parceiros autorizados. Os (as) autores (as) preservam os direitos autorais, mas não têm permissão para a publicação da contribuição em outro meio, impresso ou digital, em português ou em tradução. 